\title{
TREINAMENTO DOS COLABORADORES E GESTÃO À VISTA PARA UMA BENEFICIADORA DE ARROZ
}

\author{
André Ricardo Soares - FATEC Guaratinguetá \\ andre.amarante@fatec.sp.gov.br \\ Bruna Rodrigues Oliveira - FATEC Guaratinguetá \\ bruna.rod_oliveiraa@hotmail.com \\ Gabriela Hauke Rodrigues Pinto - FATEC Guaratinguetá \\ gabriela.hauke@gmail.com \\ Patrícia de Carvalho Zangrandi - FATEC Guaratinguetá \\ patrícia.zangrandi@gmail.com \\ Sabrina de Cássia Limongi Aquino - FATEC Guaratinguetá \\ sabrina_limongi@hotmail.com \\ Thaís Garcia Conceição - FATEC Guaratinguetá \\ tha_garcia_@hotmail.com
}

\section{Resumo}

Este estudo utiliza-se dos fundamentos da Gestão de Produção para a otimização dos processos de uma Beneficiadora de Arroz, focando no treinamento dos seus colaboradores e no controle de estoques através da Gestão à Vista. A Beneficiadora faz parte de uma empresa verticalizada que opera desde a plantação, colheita, secagem, estocagem, beneficiamento e comercialização. O avanço tecnológico em maquinários e melhoramento de sementes otimizou a parte do plantio e colheita, mas, sendo uma commodity a margem de lucro do arroz é reduzida; através de melhoramentos na parte produtiva do beneficiamento pode-se aumentar a lucratividade da empresa. Sugere-se neste estudo soluções que não necessitam de investimentos elevados, mas podem impactar positivamente na lucratividade e organização da empresa. O ambiente da Beneficiadora não é propício para instalações de computadores devido a poeira e calor, então sugerimos para o controle de estoque Quadros de Gestão à Vista, possibilitando decisões estratégicas para manutenção dos estoques. 
Sugere-se também o treinamento dos colaboradores em sistema on-the-job training com a padronização dos processos, utilizando e controlando padrões, determinando a sistemática das ações e o seu direcionamento para realização das metas, trazendo o benefício de todas as operações serem descritas detalhadamente de forma que possam ser realizadas por qualquer um dos colaboradores de forma correta e segura; seguindo as etapas da melhoria sugerida, elaborou-se um novo padrão de treinamento para os colaboradores, a fim de criar uma cultura de aprimoramento contínuo, melhorar o ambiente de trabalho e eliminar os desperdícios existentes no processos produtivos e no controle dos estoques.

Palavras-chave: Gestão de Produção; Beneficiadora de Arroz; Decisões Estratégicas.

\section{Abstract}

This study is based on the fundamentals of production management for the optimization of the processes of a Rice Mill, focusing on standardization of their collaborators and on the inventory control through the Visual Management. The Mill is part of a vertically integrated company, which operates from planting, harvesting, drying, storage, processing and marketing. Technological advances in machinery and seed improvement optimized the part of the planting and harvesting, but being a commodity, rice profit margin is reduced, through improvements in the production of the processing, it can be increased the company's profitability. It is suggested in this study, solutions that do not require high investments, but can impact positively on profitability and the company's organization. The mill environment is not propitious to computer installations due to dust and heat, then, we suggest Boards to inventory control, the View Management, allowing strategic decisions to maintain stocks. It is also suggested the collaborators' training in on-the-job systems, with the standardization of the processes, using and managing patterns, determining the systematic actions and its focus on achieving the goals, bringing the benefit of all operations in order to be described in details, in order they can be performed by any of the employees properly and safely. Following the steps of improvement suggested, it was prepared a new training pattern to the collaborators, in order to create a continuous culture of improvement, to improve the working environment and to eliminate existing waste in the production processes and in the inventory control. 
Keywords: Production Management, Rice Mill, Strategic Decisions.

\section{Introdução}

A Gestão da Produção e Operações é o campo dos conceitos e técnicas aplicadas em tomadas de decisões na função produtivas (empresas industriais) e operacionais (empresas de serviço). Utiliza-se de várias disciplinas, como: estudo de tempo e métodos, fluxo do processo, processo produtivo, mapeamento da cadeia de valores, plano mestre de produção, indicadores de desempenho, identificação de problemas e gargalos, levantamento da produtividade e melhoria, processo de implementação. Através da Gestão de Produção estudamos os processos produtivos para o aumento efetivo da produção, utilizando-a na agroindústria rizicultora possibilitando melhorias no processo de beneficiamento de arroz.

Esse estudo realizou-se em uma Beneficiadora de Arroz em Guaratinguetá, São Paulo, cidade situada na região do Vale do Paraíba, importante região rizicultora do Estado de São Paulo, responsável por $50 \%$ da produção de arroz consumida pelo estado (IEA, 2015) impactando significativamente na economia da cidade. Observa-se que a rizicultura vale-paraibana aumentou consideravelmente a sua produtividade por meio de avanços tecnológicos em maquinários agrícolas e alteração genética de sementes, por ser uma commodity sua margem de lucro é estreita. Sendo assim, qualquer melhoria produtiva em sua fase de beneficiamento é considerável para o ramo.

Importante ressaltar que o arroz faz parte da alimentação básica do brasileiro, tendo influências diretas de fatores culturais e socioeconômicos, sendo um alimento com excelente balanceamento nutricional, além de ser uma cultura extremamente versátil, sendo rotulado como um dos grãos mais importantes para o combate da fome mundial (POF, 2016).

Nesse estudo apresenta-se sugestões para o Controle dos Estoques por meio da padronização dos processos e quadros de Gestão à Vista e o treinamento dos colaboradores, impactando diretamente no desempenho da qualidade, velocidade, confiabilidade e custo do beneficiamento do arroz. Essas sugestões trarão vantagens econômicas, com soluções simples e de baixo investimento, melhorando a qualidade 
do produto final e a eficácia no atendimento aos clientes, rapidez nas entregas, possibilitando vantagens estratégicas à empresa beneficiadora de arroz em estudo.

O treinamento dos colaboradores por meio da padronização dos processos, utilizando-se de on-the-job training, visa aprimorar a comunicação no ambiente corporativo e criar a mudança cultural na empresa. Com os quadros de Gestão à Vista objetiva-se controlar efetivamente os estoques, e assim evitar interrupções devido a falta de materiais ou mão de obra, além da utilização do Método Kanban, que possibilita maior fluidez na realização das funções.

A metodologia utilizada inclui pesquisa de campo para identificação de possíveis melhorias qualitativas; levantamento de dados e informações da empresa com o proprietário e colaboradores; pesquisas bibliográficas para fundamentar as possíveis sugestões de melhoria; apresentação do trabalho a nível acadêmico; esclarecimento das soluções propostas ao proprietário com suas respectivas melhorias.

\subsection{Relato Circunstanciado}

\subsubsection{Caracterização da Empresa}

A Beneficiadora de Arroz do estudo em questão, é propriedade de uma família descendente de italianos desde a década de 60, com suas atividades inicialmente voltadas a rizicultura rudimentar, horticultura e plantação de laranja. Ao longo dos anos aprimorou-se na atividade de rizicultura e aos poucos abandou as demais atividades, para direcionar-se exclusivamente ao plantio, secagem e beneficiamento do arroz. Localizada em Guaratinguetá, São Paulo, iniciou suas atividades em 1999, faz parte de uma organização maior que envolve também o plantio e a secagem do arroz, ou seja, o processo verticalizado da produção desde a plantação até chegar ao consumidor final.

Na Figura 1 observa-se a evolução da estrutura operacional da propriedade, bem com as modificações de tipos de plantio e construções pelas quais passou entre os anos de 1987, 2002 e nos dias atuais,2016, as instalações da Beneficiadora de Arroz.

A Beneficiadora de Arroz tem como seus principais produtos o Arroz Tipo I Premium, Arroz Tipo I e Tipo II, sua segmentação geográfica voltada para o Vale do Paraíba do Sul, sua distribuição nas cidades: Guaratinguetá, Lorena, Aparecida, Potim, 
Taubaté, Moreira César, Pindamonhangaba e Cruzeiro. Sua produção limitada não prevê aumento de mercado a curto e médio prazo.

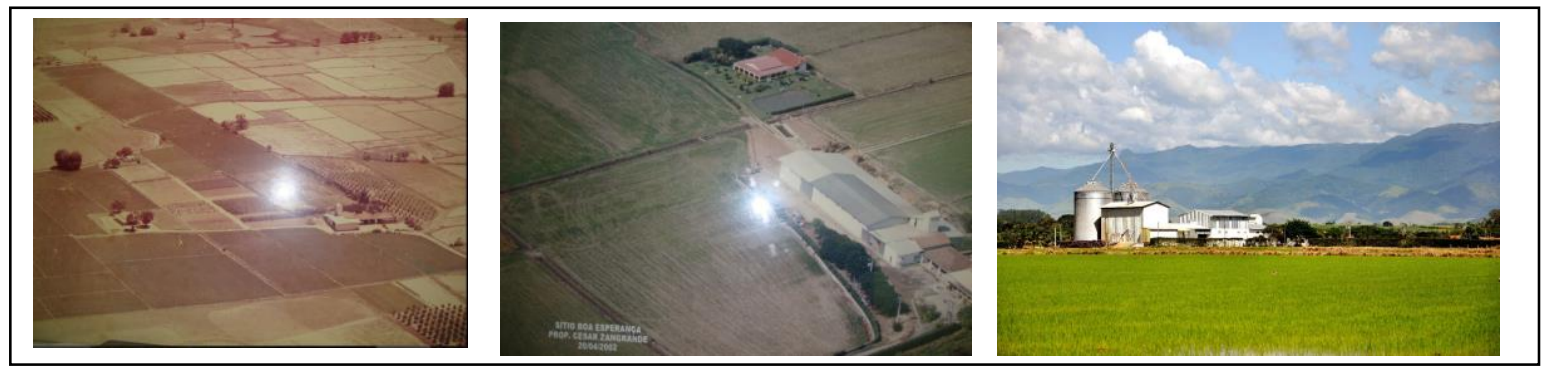

Figura 1 - Anos 1987/2002/2016, Instalações da Beneficiadora de Arroz respectivamente Fonte: Beneficiadora de Arroz

\section{Estrutura da Empresa}

\subsection{Instalações}

A propriedade em que se situa a Beneficiadora tem área de 6 alqueires, estrutura de barracão de $2.300 \mathrm{~m}^{2}$, sendo que a área de ocupação da Beneficiadora é de $987,48 \mathrm{~m}^{2}$. Os demais espaços são ocupados para o descarregamento do arroz colhido, pré-limpeza, secagem e colocação dos silos.

A parte referente à Beneficiadora divide-se em três setores distintos e alocados de maneira a facilitar o processo produtivo: setores de produção, logística e administração. O setor de Contabilidade é terceirizado e localiza-se na cidade de Potim, sendo que os seus dados contábeis são transmitidos por meio de sistema computadorizado. O sistema integrado utilizado é o Administrador WINCOM.

Todos os transportes de matérias primas são automatizados por meio de esteiras e elevadores, dispensando mão de obra para essas funções, e a alocação das máquinas é imprescindível para facilitar o transporte automatizado dos materiais.

O layout é um arranjo físico que funciona como "planta baixa", na verdade representa uma descrição física no plano horizontal. Segundo Préve (2012) o layout se define pela posição que viabiliza, em um determinado espaço físico, a realização das atividades e o fluxo de agentes e de materiais, ou ainda, é um instrumento que permite o necessário suporte para a estruturação e desenvolvimento de processos. 
O Setor de Produção, com aproximadamente $640 \mathrm{~m}^{2}$, consta com as seguintes máquinas: Descascador, Marinheira, Trieur, Brunidor, Mesa Classificadora, Seletron e Empacotadeira, além de três silos menores dentro do barracão, com capacidade de 60 toneladas cada um deles, sendo que dois deles estocam arroz integral e o terceiro arroz em casca. Consta também com dois silos grandes fora do barracão com capacidade de 360 toneladas cada um deles, sendo que estes fazem parte da cadeia produtiva da colheita e secagem, e um estoque de emergência de arroz descascado, localizado ao lado do Brunidor.

O Setor de Logística, com aproximadamente $290 \mathrm{~m}^{2}$, conta com estoque estratégico de produto acabado (aproximadamente $94 \mathrm{~m}^{2}$ ), o estoque de embalagens, esteiras de carregamento, paletes, carrinhos hidráulicos e o caminhão de entrega.

O Setor Administrativo, com aproximadamente $62 \mathrm{~m}^{2}$, conta com o escritório que recebe os pedidos e solicita as entregas, além de enviar os dados contábeis para a contadora.

Os setores são demonstrados no Layout da Beneficiadora de Arroz, na Figura 2.

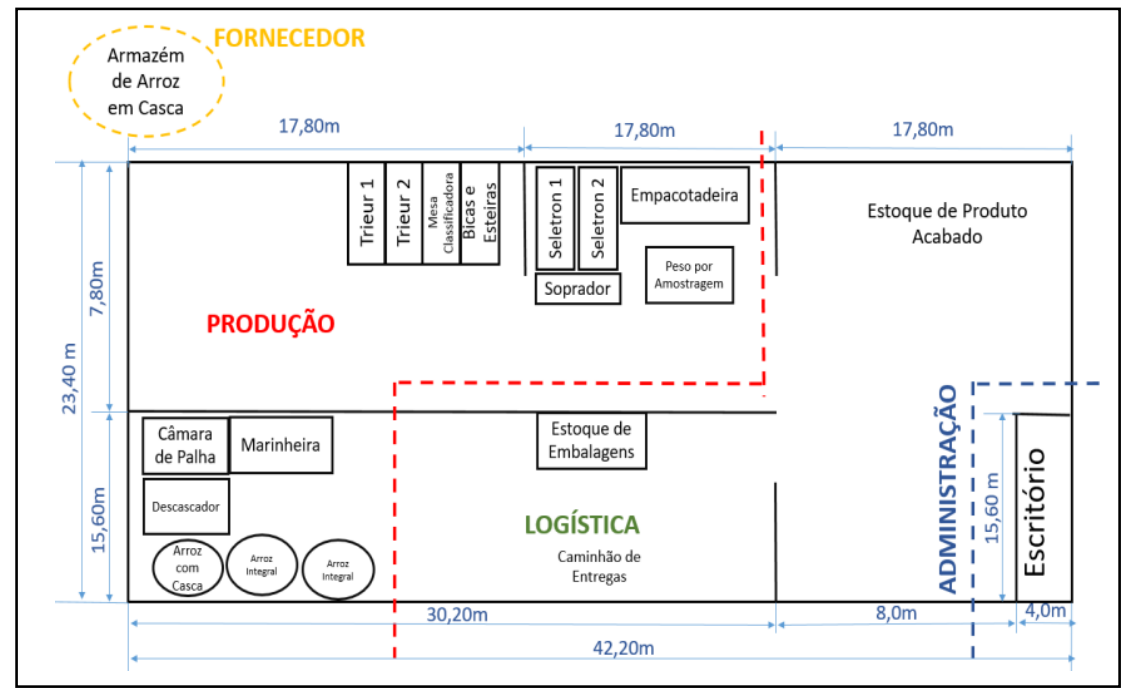

Figura 2 - Layout da Beneficiadora de Arroz Fonte: Os autores 


\subsection{Estrutura Organizacional Formal}

A Estrutura Organizacional Formal ou Organograma de uma empresa deve ter suas atividades bem identificadas, ou seja, deve-se estabelecer a ordem correta de todas as suas atividades, bem como os níveis hierárquicos de seus colaboradores, visando o estabelecimento dos limites e/ou decisões de cada nível. Desta forma a empresa pode estabelecer um planejamento para que seus objetivos sejam alcançados.

Segundo Curto Jr.(2011), organograma é uma espécie de diagrama usado para representar as relações hierárquicas dentro de uma empresa, ou, de maneira mais simples, a distribuição dos setores, unidades funcionais e cargos e a comunicação entre eles.

Podemos observar a Estrutura Organizacional Formal ou Organograma da Beneficiadora de Arroz na Figura 3, sendo uma estrutura departamentalizada com 5 colaboradores multifuncionais, além de dois colaboradores terceirizados.

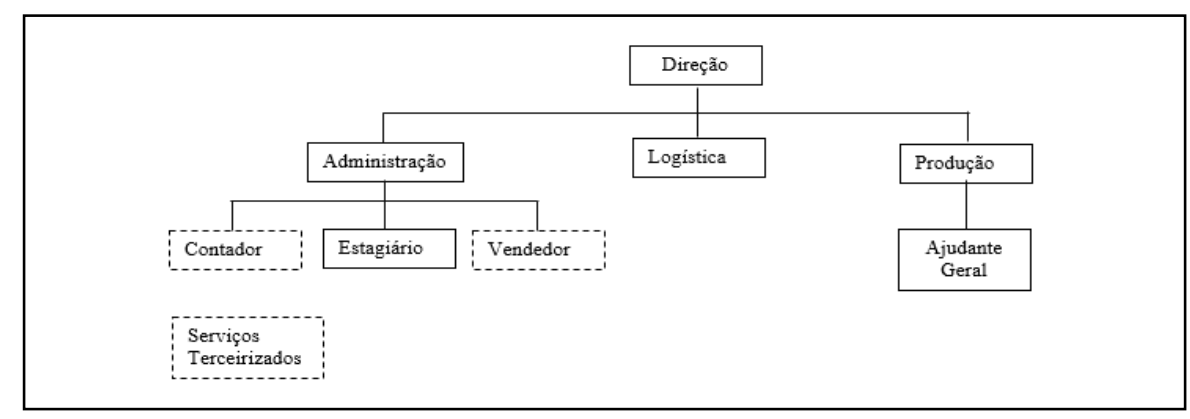

Figura 3. Organograma da Beneficiadora de Arroz Fonte: Os Autores

\section{Processo Produtivo}

O Processo Produtivo da Beneficiadora de Arroz inicia-se com três tipos de estoques iniciais: Estoque de Arroz em Casca e Estoque de Arroz do Sul (Beneficiado) e embalagens.

Durante o processo do arroz em casca extrai-se os subprodutos: casca de arroz, arroz integral, farelo de arroz, arroz $3 / 4$ e $1 / 2$ arroz; e os produtos principais Arroz Premium, Arroz Tipo I e Arroz Tipo II. O processo produtivo é todo automatizado, com 
exceção do enfardamento, conforme é demonstrado na Figura 4, com as porcentagens de cada subproduto e as respectivas máquinas envolvidas no processo.

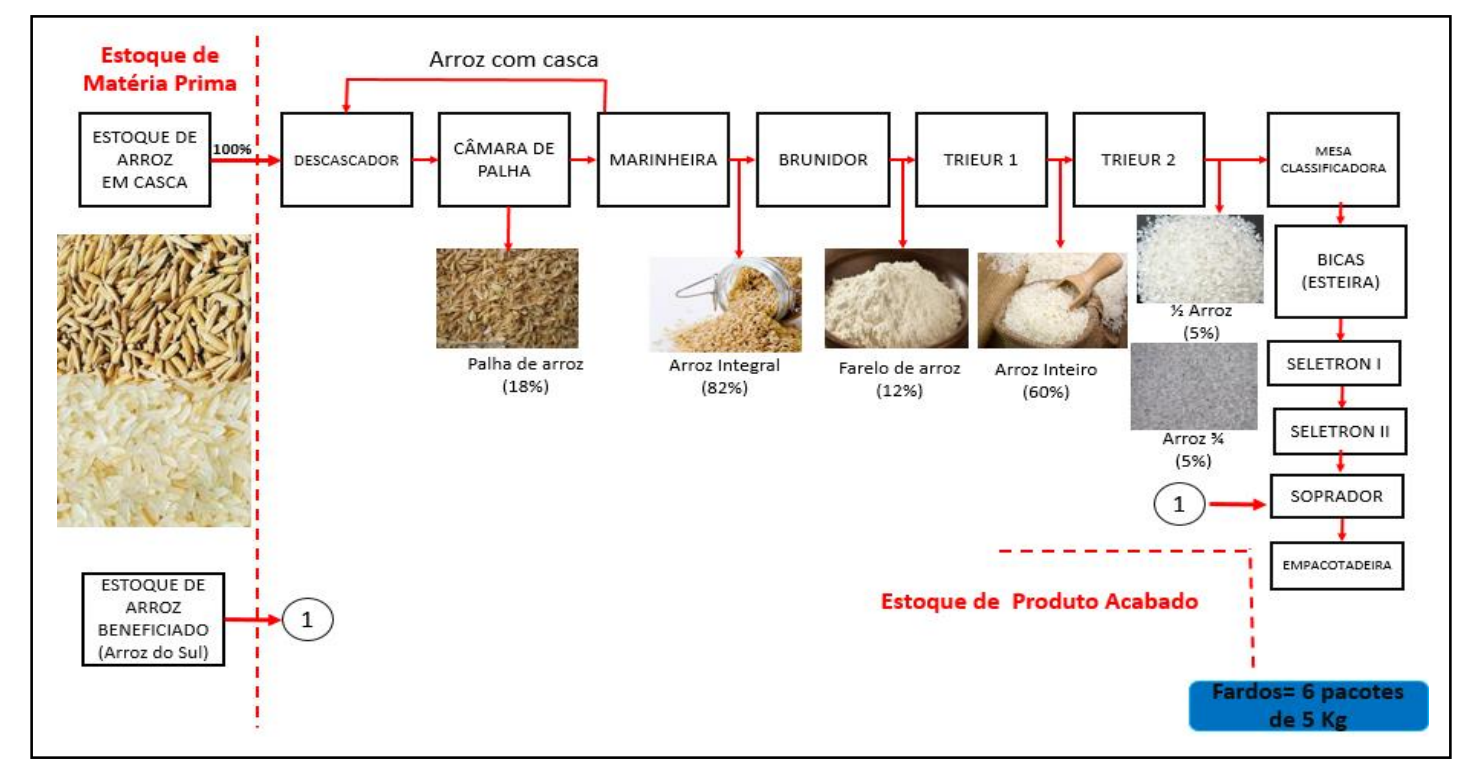

Figura 4. Processo Produtivo da Beneficiadora de Arroz Fonte: Os autores

\subsection{Fluxograma}

O fluxograma serve para demonstrar a sequência dos processos realizados para determinada produção, ou seja, quais passos e em que ordem devem ser realizadas para que realização de tal tarefa.

Segundo Curto Jr.(2011), um fluxograma ou flowchart, é um diagrama que tem como finalidade representar processos ou fluxos de materiais e operações, utilizando diagramação lógica ou de fluxo.

Na Figura 5 observa-se o Fluxograma da Beneficiadora de Arroz e os pontos em que haverá a utilização dos Quadros de Gestão à Vista para o Controle de Estoques e o Treinamento dos colaboradores. 


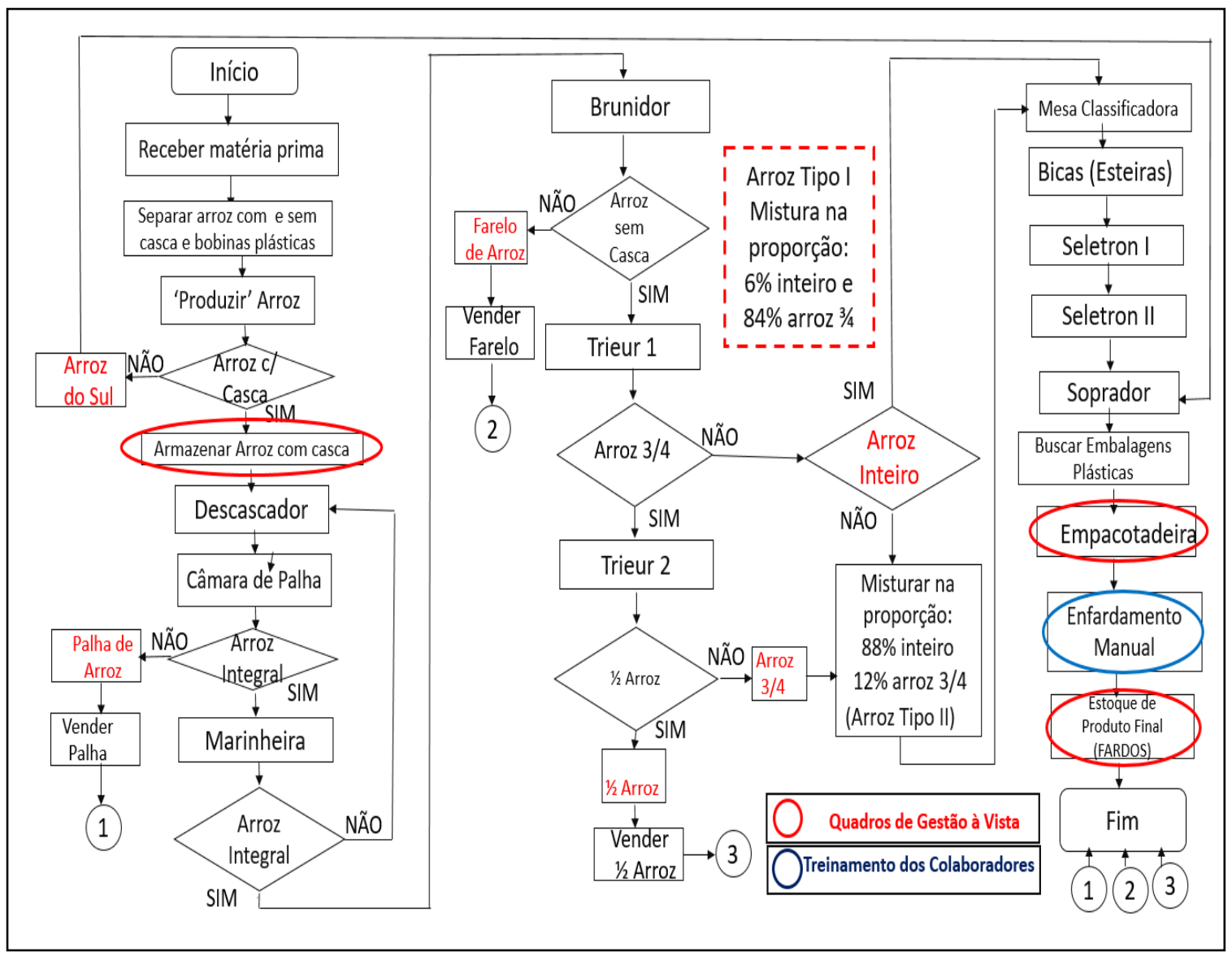

Figura 5. Fluxograma da Orizícola

Fonte: Os autores

\section{Análise dos Processos Encontrados}

Para atuar na melhoria qualitativa do beneficiamento de arroz utilizaremos o Ciclo PDCA (Plan, Do, Check, Action). Segundo o Portal Infoescola (2016) (www.infoescola.com), o controle de processos e solução de problemas, compõem-se de quatro fases: Planejar (Plan), Executar (Do), Verificar (Check) e Agir (Action).

Neste projeto foram realizadas as três primeiras fases do Ciclo PDCA: planejouse as possíveis melhorias, executou-se como deveriam ser realizadas e verificou-se as melhorias.

O Ciclo PDCA utiliza-se de várias ferramentas da qualidade, sendo que o uso delas não garante a resolução dos problemas, garante apenas seu entendimento. 
Utilizou-se as seguintes ferramentas da Qualidade: Brainstorming, GUT (Gravidade, Urgência e Tendência), Diagrama de Ishikawa.

\subsection{Brainstorming}

O grupo de estudos juntamente com os colaboradores da empresa realizou uma tempestade de ideias, Brainstorming, para listar-se os principais problemas percebidos no processo produtivo do beneficiamento do arroz.

Segundo a Manufacturing Terms (2016) (www.manufacturingterms.com), Brainstorming é uma técnica de criatividade do grupo com finalidade de gerar um grande número de ideias para a solução de um problema.

\subsection{GUT}

Após a realização do Brainstorming, passou-se a priorização dos problemas encontrados por meio da Matriz GUT.

Segundo Scartezini (2009), a GUT é uma forma de priorização baseado em medidas ou observações subjetivas. Gravidade refere-se ao impacto do problema sobre os processos, pessoas, resultados, ao custo por deixar de tomar uma ação que poderia solucionar o problema; Urgência relaciona-se com o tempo disponível, ou o necessário, para resolver o problema, análise e melhoria de processo; Tendência refere-se ao rumo ou propensão que o problema assumirá se nada for feito para eliminar o problema. Com os todos os problemas listados realizou-se uma priorização dos problemas através da GUT, mostrada na Tabela 1.

Observa-se que os itens mais relevantes, de maior pontuação, da Tabela GUT estão demarcados em cores amarelas e vermelhas, sendo que os itens demarcados na cor amarela serão os abordados nas melhorias propostas por sua aplicabilidade e possibilidades reais de melhorias; enquanto os demarcados em vermelho, apesar de também apresentarem grande relevância quanto a melhorias, foram descartados pelo gestor da Beneficiadora de Arroz, que não almeja realizar investimentos significativos a curto e médio prazo na empresa. 
Tabela 1. GUT da Beneficiadora de arroz

\begin{tabular}{lcccc}
\hline \multicolumn{1}{c}{ PROBLEMAS ENCONTRADOS } & G & U & T & GUT \\
\hline Tabela da CONAB (Companhia Nacional de Abastecimento) - KPI de Custo & 3 & 3 & 3 & 27 \\
\hline Falta de Controle dos Estoques & 5 & 5 & 5 & 125 \\
\hline Estoques Intermediário: KPI de Velocidade & 5 & 5 & 4 & 100 \\
\hline Estoques de Subprodutos: KPI de Flexibilidade & 2 & 3 & 2 & 12 \\
\hline $\begin{array}{l}\text { Utilização da Capacidade de Estoque: KPI's de Flexibilidade, Custo } \\
\text { Confiabilidade }\end{array}$ & 4 & 5 & 5 & 100 \\
\hline Padronização do Estoque: KPI's de Flexibilidade e Confiabilidade & 5 & 5 & 5 & 125 \\
\hline Controle do Estoque de Embalagens Plásticas: KPI de Confiabilidade & 5 & 5 & 5 & 125 \\
\hline Capacidade do Caminhão: KPI de Velocidade e Custo & 2 & 2 & 2 & 8 \\
\hline Descascador: KPI's Qualidade, Flexibilidade e Qualidade & 2 & 2 & 2 & 8 \\
\hline Câmara de Palha: KPI's Qualidade e Flexibilidade & 2 & 2 & 2 & 8 \\
\hline Marinheira: KPI Qualidade & 2 & 2 & 2 & 8 \\
\hline Brunidor: KPI de Flexibilidade & 2 & 2 & 2 & 8 \\
\hline Mesa Classificadora e Bicas: KPI de Flexibilidade & 2 & 2 & 2 & 8 \\
\hline Seletrons: KPI de Qualidade e Flexibilidade & 3 & 3 & 2 & 18 \\
\hline Soprador: KPI de Qualidade & 3 & 2 & 2 & 12 \\
\hline $\begin{array}{l}\text { Empacotadeira: Treinamento dos colaboradores por meio da Padronização } \\
\text { do Processo (KPI de Qualidade e Flexibilidade) }\end{array}$ & 5 & 5 & 5 & 125 \\
\hline Enfardamento Manual e não automático & & & \\
\hline Mau Funcionamento do conjunto: Trieur, Brunidor, Mesa Classificadora & 5 & 5 & 5 & 125 \\
\hline
\end{tabular}

Fonte: Os autores

\subsection{Diagramas de Ishikawa}

Para determinar as causas dos problemas priorizados utilizamos Diagramas de Ishikawa, sendo que o segundo diagrama é um desmembramento do primeiro. Desta forma estabelece-se as maneiras que as causas e, consequentemente, os problemas, serão abordados para as melhorias sugeridas. Segundo Roth (2011), o Diagrama de Ishikawa recebe esse nome devido ao seu criador, ou Espinha de Peixe, devido ao seu formato, é uma forma gráfica usada como metodologia para a análise e representação dos fatores de influência (causas) sobre um determinado problema (efeito).

Os problemas estudados são: Falta de controle de estoques para atender a demanda e Falta de treinamento dos colaboradores, sendo mostrados os seus diagramas nas Figuras 6 e 7, respectivamente. 


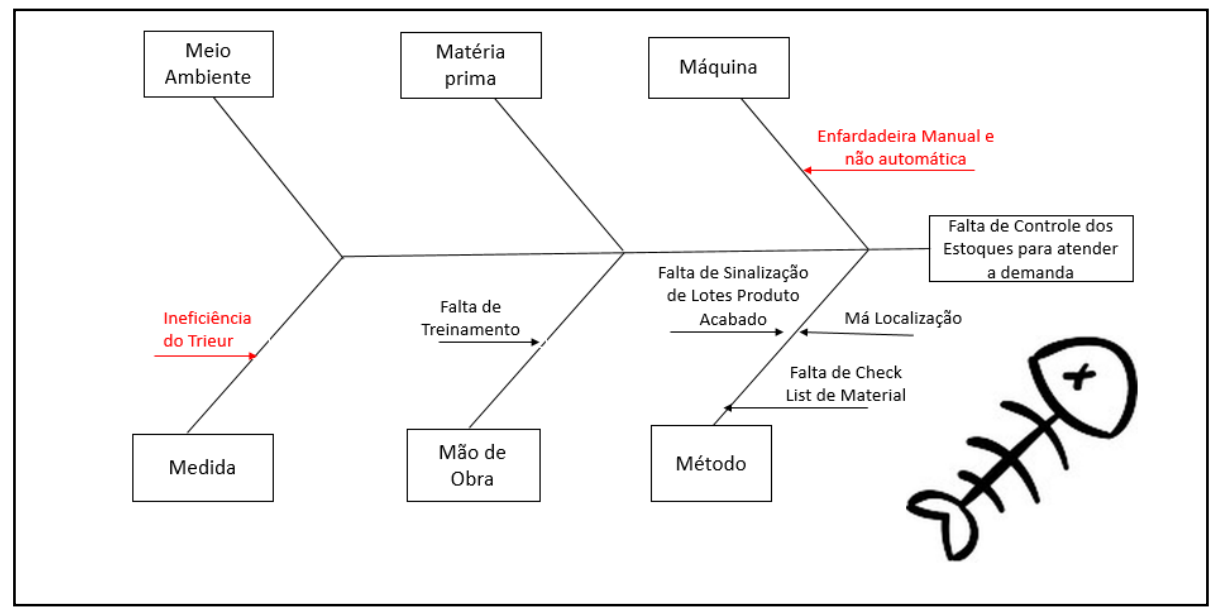

Figura 6. Diagrama de Ishikawa - Falta de Controle dos Estoques para atender a demanda Fonte: Os autores

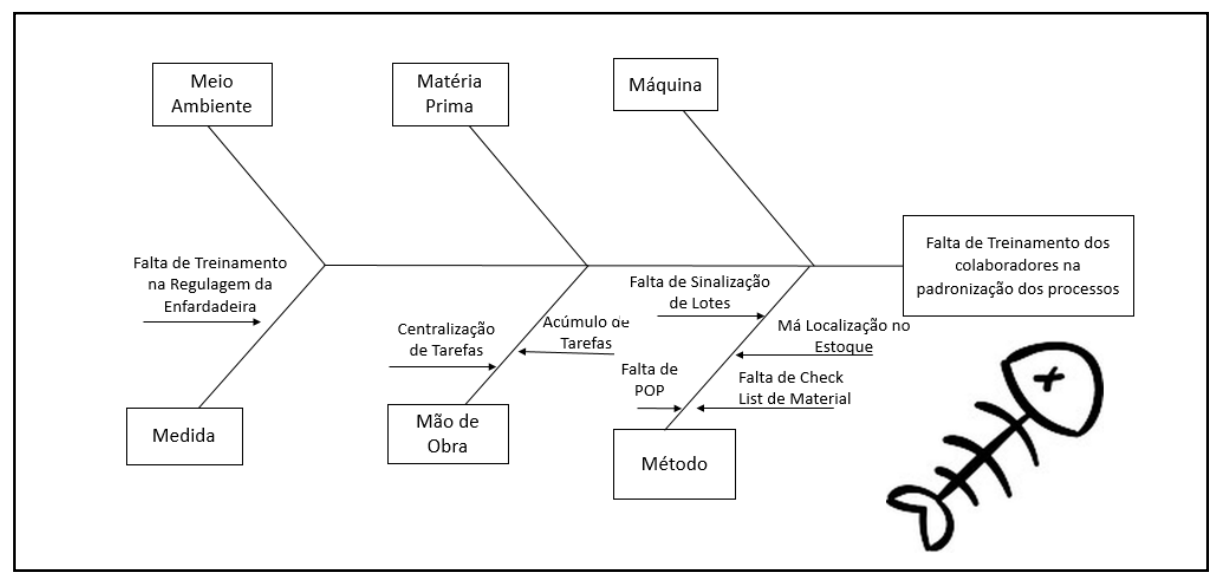

Figura 7. Diagrama de Ishikawa - Falta de Treinamento dos colaboradores Fonte: Os autores

Os problemas de enfardamento manual (tendo sugestão de melhoria o enfardamento automático) e o mau funcionamento do conjunto (tendo como sugestão a troca completa do conjunto Trieur, Brunidor e Mesa Classificadora) foram excluídos da possibilidade de melhoria pelo alto custo de investimento, visto que gestor da empresa já havia relatado anteriormente não desejar investimentos de alto valor a curto ou médio prazo.

Em pesquisa de mercado o preço da enfardadeira automática foi cotado em aproximadamente em $\mathrm{R} \$ 11.000,00$ e o conjunto Trieur, Brunidor e Mesa classificadora foi cotado em $R \$ 1.300 .000,00$. 


\section{Propostas do Plano de Ação}

A metodologia proposta para o plano de ação da Beneficiadora de Arroz aproxima-se do PCP (Planejamento e Controle de Produção), fazendo-se planejamento, direção e controle do suprimento de materiais e atividades de processamento. As principais atribuições do PCP são: definição das quantidades a produzir, gestão de estoque, emissão de ordens de produção, programação das ordens de fabricação e acompanhamento da produção (Roth, 2011).

\subsection{EAP (Estrutura Analítica de Projetos)}

Segundo Carvalho; Rabechini Jr.(2015), a EAP é um processo de decomposição dos resultados principais, mostrado pela representação hierárquica de todo o trabalho do projeto. Importante ressaltar que deve-se evitar os extremos, pouca decomposição pode significar estimativas grosseiras nos pacotes de trabalho, enquanto muita decomposição perde a finalidade gerencial por se aproximar das listas de atividades (cronograma).

Foi desenvolvida e apresentada a EAP, com as melhorias apresentadas, bem como os Procedimentos Operacionais Padrão, para orientar as implementações na mesma. Em função da extensão da EAP desenvolvida, não foi possível contemplar a mesma no artigo.

\subsection{Mapeamento da Cadeia de Valores da Beneficiadora de Arroz}

O Mapeamento da Cadeia de Valores permite que o gestor identifique os processos que agregam e não agregam valor ao processo produtivo, possibilitando alterações que permitam vantagem competitiva para a organização. Segundo o MPF, Ministério Público Federal (2013), o gerenciamento correto de uma cadeia de valores pode ser um diferencial competitivo, melhorando a rentabilidade da organização, por meio da identificação e eliminação de atividades que não adicionam valor ao produto. $\mathrm{A}$ análise da cadeia de valores possibilita: identificar as fontes de vantagem competitiva; rever as práticas do negócio e antecipar tendências do mercado; declarar as regras utilizadas na empresa; manual de gestão de processos; visão completa do fluxo de informações 
entre os processos; evoluir o desempenho; detectar posicionamento estratégico e realinhamento dos processos.

Observa-se na Figura 9 o Mapeamento da Cadeia de Valores da Beneficiadora de Arroz, bem como as porcentagens de valores agregados e não agregados desse processo.

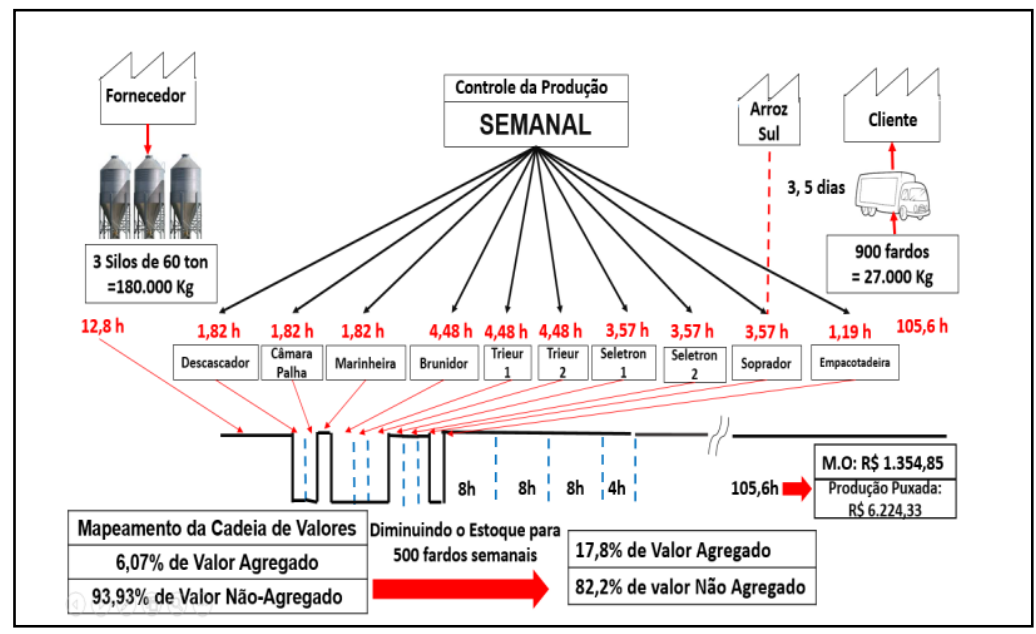

Figura 9. Mapeamento da Cadeia de Valores da Beneficiadora de Arroz

Fonte: Os autores

Observa-se que no Mapeamento da Cadeia de Valores, através do Controle de Estoques por meio dos Quadros de Gestão à Vista, implementando o Estoque De Produtos Acabados para uma quantidade de 500 fardos semanais, ao invés dos 900 fardos atuais, tendendo a uma produção puxada, aumenta-se o Valor Agregado da Produção em $11,73 \%$, trazendo um retorno inicial para a produção puxada de $\mathrm{R} \$$ $6.224,33$ e um retorno semanal de mão de obra de $R \$ 1.354,85$.

\subsection{Sistemas Integrados de Gestão}

Em um processo de tomada de decisão, a gestão eficiente da informação é dos fatores principais para um eficaz planejamento estratégico, fato que decorre do bom uso de recursos da Tecnologia da Informação. Segundo Infowester (2016), a Tecnologia da Informação (TI) define-se como o conjunto de todas as atividades e soluções desenvolvidas por recursos computacionais que visam permitir a obtenção, o armazenamento, o acesso, o gerenciamento e o uso das informações. Beneficiadora de Arroz conta com uma arquitetura simples, um PC Intel Core i3, HP Laser Jet 
P1102W, uma Rede Provale (via rádio) e Sistema ERP (WINCOM) instalado, utilizando somente o seu módulo contábil (Emissão de Notas Fiscais e Boletos para Pagamento). Sugere-se a utilização desse sistema, em combinação com os Quadros de Gestão à Vista, para o Controle dos Estoques (Matéria prima e Produtos acabados), além de um notebook redundante e realização diárias de Backup em Nuvem e em HD Externo. Observa-se na Figura 10 a arquitetura atual da empresa e a sugerida, respectivamente.

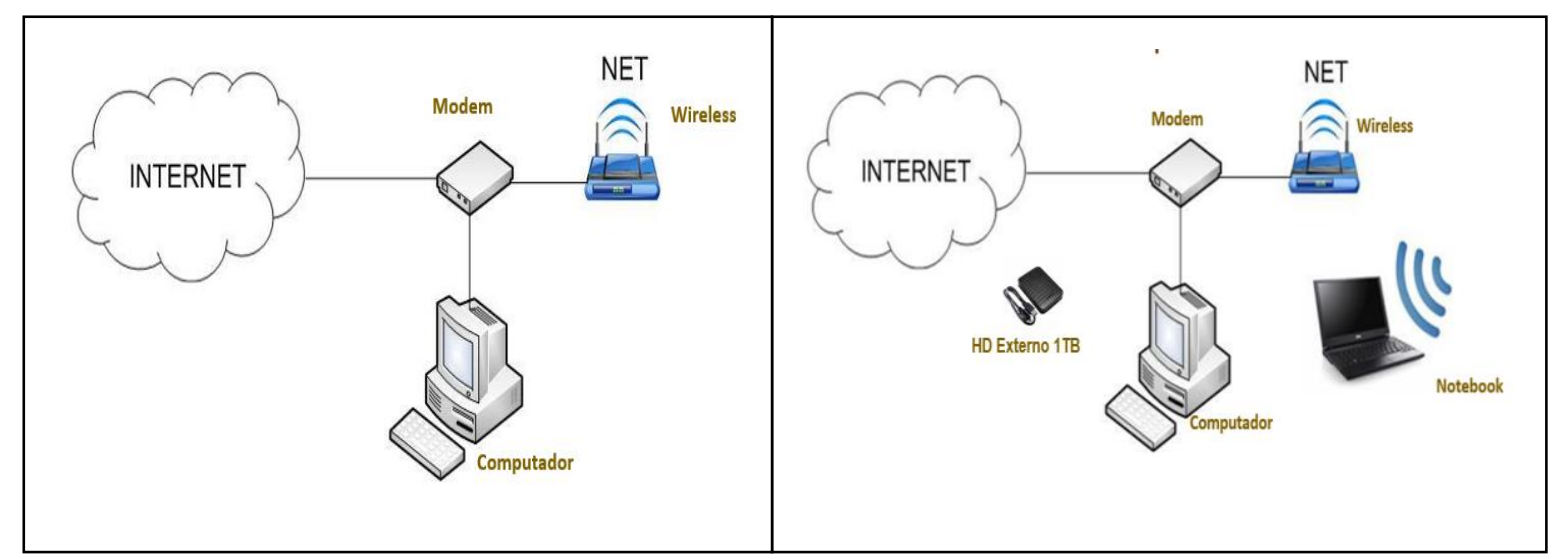

Figura 10. Arquitetura Atua e Sugerida do SI da Beneficiadora de Arroz Fonte: Os autores

\subsection{Investimentos}

Segundo Procurement Compras \& Supplychain Academy (2016) a Matriz Kraljic é um modelo estratégico, auxiliando um profissional de compras a definir suas prioridades, com base no posicionamento estratégico de cada fornecedor ou carteira de compras.

Através da Matriz de Aquisições (Matriz Kraljic) observa-se que os investimentos são de produtos não críticos e não tem necessidade de grandes investimentos, utilizando-se o retorno de duas semanas de mão de obra com a diminuição do Estoque de Produto Acabado por meio de Quadros de Gestão à Vista já se tem o retorno desse investimento, tornando-o muito atrativo à Beneficiadora de Arroz. 


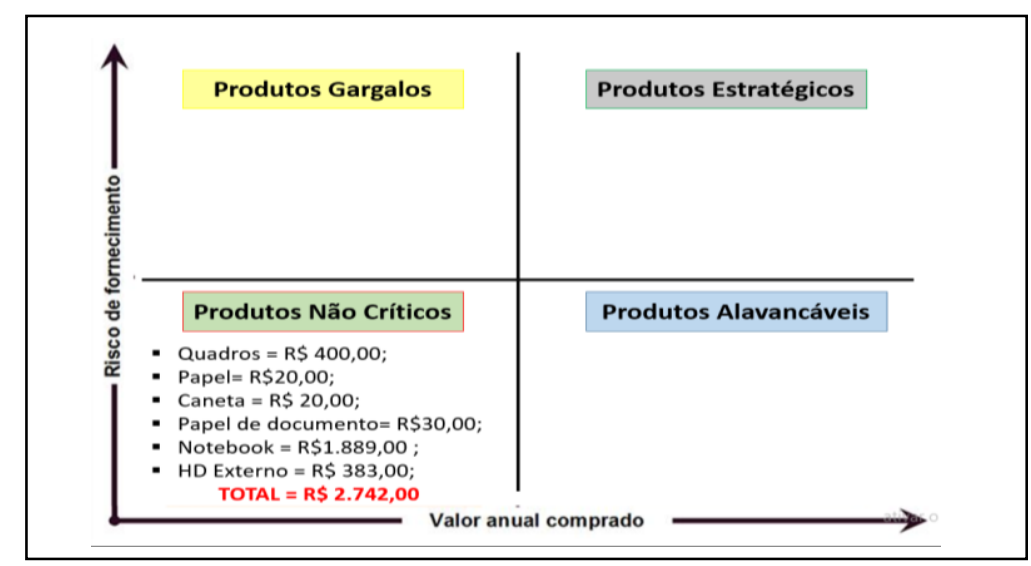

Figura 11: Matriz de Aquisições (Matriz Kraljic) da Beneficiadora de Arroz Fonte: Os Autores

\section{Considerações Finais}

Ao fim do estudo realizado na Beneficiadora de Arroz concluiu-se que a utilização de Quadros de Gestão à Vista para o controle dos estoques traz aumento de 11, 73\% no valor agregado do Mapeamento da Cadeia de Valores, com atuação no Estoque de Produto Acabado, passando-o para o valor da demanda semanal, sem a quantidade de segurança de 400 fardos semanais a mais, utilizada atualmente. Para certificar-se da integridade dos dados coletados sugeriu-se também a aquisição de um notebook e um HD Externo de 1 TB como redundância, preservando o funcionamento contínuo do controle de estoques. O retorno do investimento feito realiza-se em duas semanas de mão de obra poupada para a realização dessa tarefa. O processo de beneficiamento de arroz tenderá a produção puxada, não necessitando de estoque excedente de produto acabado, trabalhando 


\section{Referências Bibliográficas}

CARVALHO, Marly; RABECHINI JR., Roque. Fundamentos em Gestão de Projetos. Construindo competências para gerenciar projetos. 4ª ed. São Paulo: Atlas,2015.

CURTO Jr., Renato M. Organização, Sistemas e Métodos. Instituto Federal do Paraná. E-Tec Brasil: Curitiba, 2011

INFOWESTER. O que é Tecnologia de Informação (TI)? Disponível em <http://www.infowester.com/ti.php>. Acesso em 06 de nov.2016.

INSTITUTO DE ECONOMIA AGRÍCOLA - IEA. Banco de dados. São Paulo: IEA. Disponível em: <http://www.iea.sp.gov.br/out/bancodedados.html>. Acesso em: maio 2015.

PORTAL INFOESCOLA. PDCA (Plan, do, check, action). Disponível em: $<$ http://www.infoescola.com/>. Acesso em 23 de nov.2016.

MANUFACTURING TERMS - Definition at a click alway. Brainstorming. Disponível em <http://www.manufacturingterms.com/Portuguese/Brainstorming.html>. Acesso em: 25 de out. 2016.

MINISTÉRIO PÚBLICO FEDERAL - MPF. Manual de Gestão de Processos. Secretaria Jurídica e de Documentação Escritório de Processos Organizacionais do MPF. Brasília, 2013. Disponível em: <http://www.mpf.mp.br>. Acesso em: 25 out.2016.

PESQUISA DE ORÇAMENTOS FAMILIARES - INSTITUTO BRASILEIRO DE GEOGRAFIA E ESTATÍSTICA - POF - IBGE. Disponível em: $<w w w . i b g e . g o v . b r / h o m e / e s t a t i ́ s t i c a />$. Acesso em: 20 fev. 2016.

PRÉVE, Altamiro. Organização, Sistemas e Métodos. Universidade Federal de Santa Catarina. Centro Socioeconômico, Departamento de Ciências da Administração. Santa Catarina, 2012. 
PROCUREMENT COMPRAS \& SUPPLYCHAIN ACADEMY. Kraljic, Foco estratégico em compras é mais importante que você imagina. Disponível em: <http://procurementacademy.com.br/>. Acesso em: 23 nov. 2016.

ROTH, Claudio. Qualidade e Produtividade. Santa Maria: UFSM, 2011

SCARTEZINI, Luís. Análise e Melhoria de Processos. Goiânia, 2009. Disponível em: http://www.aprendersempre.org.br/ em 25 out. 2016. 